\title{
Construction of high-rise buildings in the Far East of Russia
}

\author{
Sergey Kudryavtsev ${ }^{1}$, Semen Bugunov ${ }^{1 *}$, Evgeniya Pogulyaeva $^{1}$, Anastasiya Peters ${ }^{1}$, \\ Zhanna Kotenko ${ }^{1}$ and Danil Grigor'yev ${ }^{1}$ \\ ${ }^{1}$ Far Eastern State Transport University, Seryshev st., 47, Khabarovsk, 680021, Russia
}

\begin{abstract}
The construction of high-rise buildings on plate foundation in geotechnical conditions of the Russian Far East is a complicated problem. In this respect foundation engineering becomes rather essential. In order to set a firm foundation it is necessary to take into account the pressure distribution at the structure base, in homogeneity of building deformation, which is due to collaborative geotechnical calculations complicated by a number of factors: actual over-placement of soils, the complex geometry of the building under construction, spatial work of the foundation ground with consideration for physical nonlinearity, the influence of the stiffness of the superstructure (reinforced concrete framing) upon the development of foundation deformations, foundation performance (the performance of the bed plate under the building and stairwells), the origination of internal forces in the superstructure with differential settlement. The solution of spatial problems regarding the mutual interaction between buildings and foundations with account of the factors mentioned above is fully achievable via the application of numerical modeling methodology. The work makes a review of the results of high-rise plate building numerical modeling in geotechnical conditions of the Russian Far East by way of the example of Khabarovsk city.
\end{abstract}

\section{Introduction}

Year by year the problem of getting new construction areas in megapolises and big cities is becoming more and more complicated because of the fact that the land price is very high. To solve this problem we have to get the max square meters quantity from each land area by means of increasing the storey number of a building.

The construction of high-storey buildings in the field of residential real estate reduces the price for a land square meter and makes it possible to decrease the price for ready housing constructions. All of the current technical difficulties are quite resolvable.

The building-up of high-storey building on plate foundation constructions in engineeringgeological conditions of Khabarovsk is a complicated geotechnical goal and it is acceptable only if there is special geotechnical ground for it.

In connection with this the installation of safe foundation and base is quite urgent.

\footnotetext{
*Corresponding author: soymaa@inbox.ru
} 
The main condition of safe foundation and base installation is the functional pressure distribution which exists in base, and also the clearance of building strain variations. The consistent assessment of these data in calculations is possible only on the base of careful geotechnical tridimensional calculations, which allow taking into consideration a lot of basic real factors:

- Soil formations; complicated geometry of a raising building;

- Space combined action of foundation soil taking into account the physical nonlinearity of an above ground construction;

- Influence of above ground constructions (concrete core) stiffness on rearrangement of base strain variations and etc.

While considering the space combined plans about building and ground interaction it makes sense to take into account the quoted factors in full with the help of numerical model method by combined finite strip-finite element method.

In the "base - foundation - high storey building" system the main role in keeping the constructional integrity is played by bases both during the building process and in the period of its exploitation. The safety of a future construction depends on resistibility of a base floor material and also on the level of deflectivity on load.

\section{Materials and methods}

\subsection{Geotechnical conditions of Khabarovsk}

Khabarovsk is "a city on three hills" and benches of the Amur. The city and the surrounding areas are situated within one of the largest trenches in The Far East - Middle-Amurskaya trench. On its territory one can find areas filled by Cenozoic poorly cemented continental buildups and also elevations made by more ancient and tough Paleozoic and Mezozoic aqueous and anogene rocks.

Khabarovsk and its surroundings are situated in severe climatic conditions with various landscape and quite diverse soil structures which you have to deal with on all the levels of building.

All rocks within the considered territory can be divided into to large groups: rocks of original base and superficial deposits.

The most important peculiarity of geological formation is the inhomogenuity of its formation, considerable variability of strength and deformational features of sedentary units. All of these factors in accordance with the normative requirements must be taken into consideration when engineering and carrying out works within the limits of the city.

Judging by the abovementioned information it makes sense to conduct the construction of buildings in the city of Khabarovsk taking into account the engineering-geological conditions, and also by using protective and preventive measures from adverse impact of different natural and industrial factors.

\subsection{Research of stress strain behavior of high-rise buildings on plate foundation}

The analysis of the the "base - foundation - high storey building" system was made by finite element method with the usage of bundled software "FEM Models" developed by the staff of LLC "Pi "Georeconstruction" under the charge of professor V.M. Ulitskiy, St.Petersburg. In the calculations they used elastic-plastic model of soil base in the form of volume elements with the Mor-Kulon strength condition and equivoluminar flow rule. Walls, floor structures, ground slabs are the elastic elements of a thick plank. Columns are the elastic shanks [1-3]. 
The analysis of the numeric model engineering results of high-storey buildings on plate foundation in Khabarovsk for different engineering-geological conditions and construction solutions has also been made:

- 23-storey single-section with crawlway domestic building located on the shore face of the Amur (plate bulk $0,8 \mathrm{~m}$ )

- 25-storey building of complicated configuration with the underground parking lot situated in the northern part of Khabarovsk (plate bulk $1 \mathrm{~m}$ )

- domestic building of variable storey number (12 and 14) with in-built shop, offices and parking lot (plate bulk $0,9 \mathrm{~m}$ )

- domestic building of variable storey number (10 and 12) with in-on-built shop and underground parking lot situated in the central part of Khabarovsk (plate bulk 0,7 m).

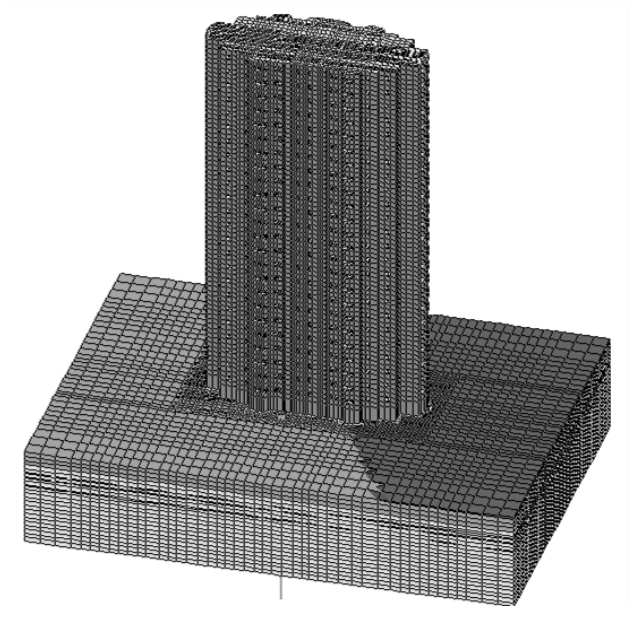

Fig. 1. Analitical model 23-storey building.

The exploration of stress strain behavior foundation of high buildings in engineeringgeological conditions of Khabarovsk has shown the following:

The gradual settlement of plate foundation was got for the buildings situated on shore face of the Amur and in the northern part of Khabarovsk.

For the building situated within the limits of the first above flood-plain bench the settlement of plate foundation had the following character: 12-storey section has differential settlement $(5-10 \mathrm{~cm})$, and the settlement of a 14-storey section is more gradual (10-11) with clearly expressed centre. It is caused by the constructional peculiarities of the building and also by the fact that within the limits of the building area there exist filled soils and their distribution is differential $(0,5-3 \mathrm{~m})$. 


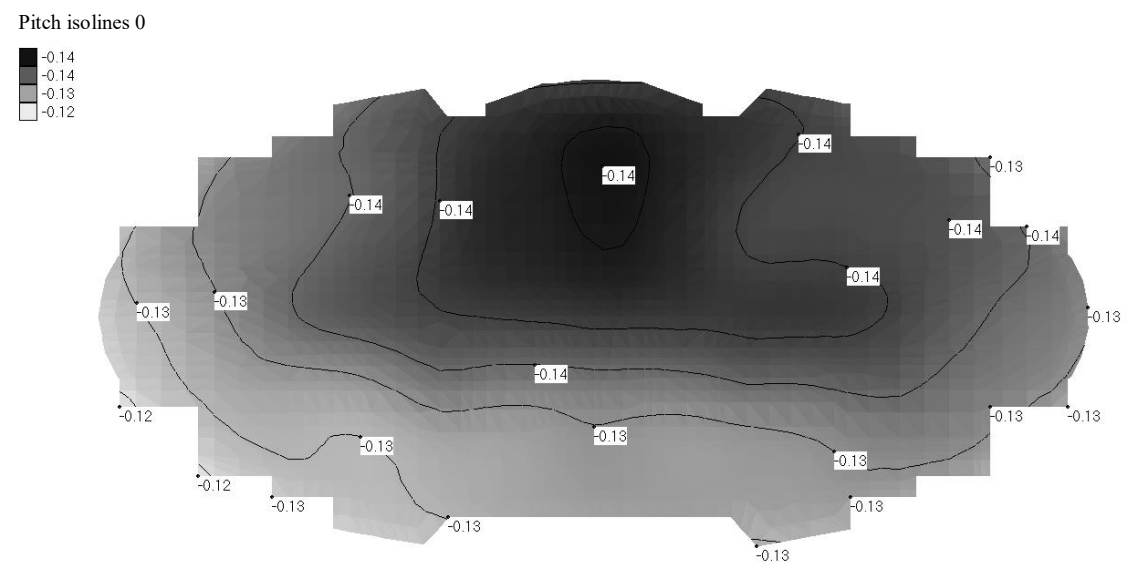

Fig. 2. Isoline of settlement plate foundation of 23 -storey building.

For the building situated in the central part of Khabarovsk the settlement of foundation plate had the following character: under the whole building area the settlement was distributed differentially. The differential settlement is caused by various depth of filled soils. Under the filled soils there are plates which are practically incompressible. The settlement is given by the filled soils.

Plate foundation makes it possible to reduce the settlement variety of a foundation plate by means of its stiffness.

During the construction of high-storey buildings with quite small underground space in the urban development area in the case when there is no opportunity to expand the foundation plate square, there exist the danger of high local pressure concentration on the soil while developing building tilts. Thus there is the necessity to check the horizontal mobility.

a)

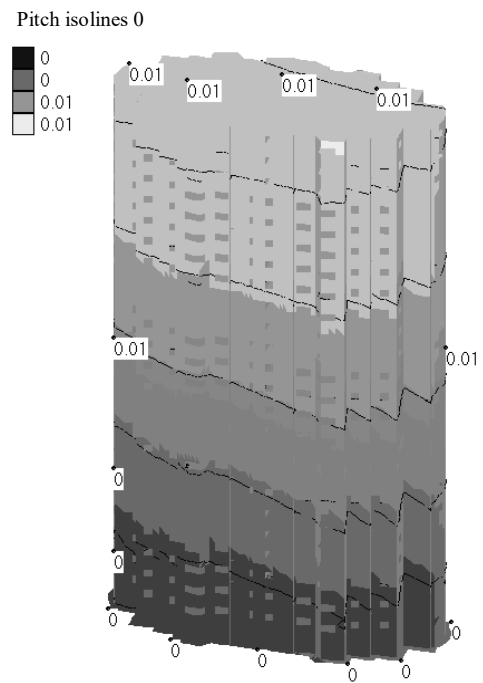

b)

\section{Pitch isolines 0.0}

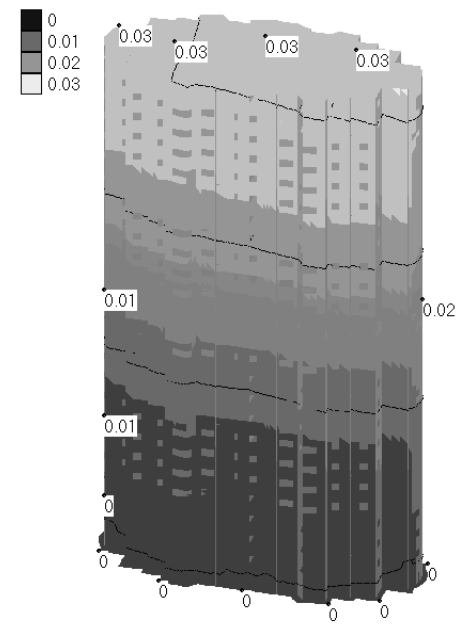

Fig. 3. Horizontal mobility of 23 -storey building: a) on the $\mathrm{X}$ axis; b) on the $\mathrm{Y}$ axis.

In our cases the horizontal mobility within the combined space calculations of the "base - foundation - high storey building" system are insignificant in relation to axis. In the lower parts of the majority of the buildings (the first 5 floors) the mobility is insignificant. On the high floors the mobility on the $\mathrm{X}$ axis reaches $0,043 \mathrm{~m}$, on the $\mathrm{Y}$ axis $-0,045 \mathrm{~m}$, which does 
not exceed admissible values. The tilt $\mathrm{i}=0,001$ is observed which does not exceed the admissible value $i_{u}=0,004 \mathrm{~m}$.

The character of the plate foundation work of the analyzed buildings in general is moving closer to a stiff mark. The local development of plastic deformation zones which do not exceed 0,25 of the plate bulk is observed under the edges.

The moments of flection which exist in foundation plate have alternating-sign amounts, the max amounts of a flection moment $\mathrm{M}_{\mathrm{x}}$ are: from minus 585 to plus 352 kilopascal and the one of $\mathrm{M}_{\mathrm{y}}$ from minus 687 to plus 543kilopascal, and the flection moment of $\mathrm{M}_{\mathrm{xy}}$ from minus 586 to plus 627 kilopascal. It points to the necessity of making plate reinforcement on two levels (the lower and high ones).

\section{Results}

\subsection{Geotechnical monitoring of deformation process of plate foundation of high-storey buildings}

To raise high buildings it is necessary to fulfill two procedures which provide safety while designing, building and exploitation: numeric model engineering of the "base - foundation high storey building" system and geotechnical monitoring in the process of building and exploitation. Fulfilling of these particular procedures allows to avoid designing mistakes and also to make the suitable correction, changing and adaptation of designing and manufacturing decisions.

These procedures were held on the levels of designing and building during the construction of multicompartment 25-storey building in Khabarovsk (figure 1).

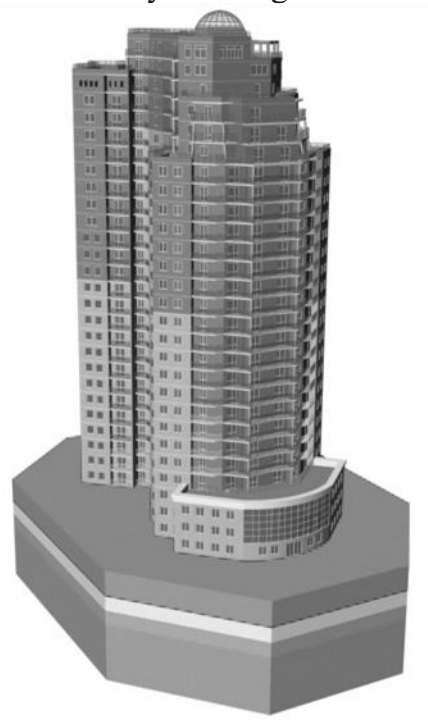

Fig. 4. Analitical model 25 -storey building.

Geological lithologic section in the sphere of designing construction interaction with geological environment in the depth interval $0-26 \mathrm{~m}$ is differential; there are 4 engineeringgeological elements in the section. Under the plate foundation the chip cab of $5 \mathrm{~m}$ depth is located (figure 2). 


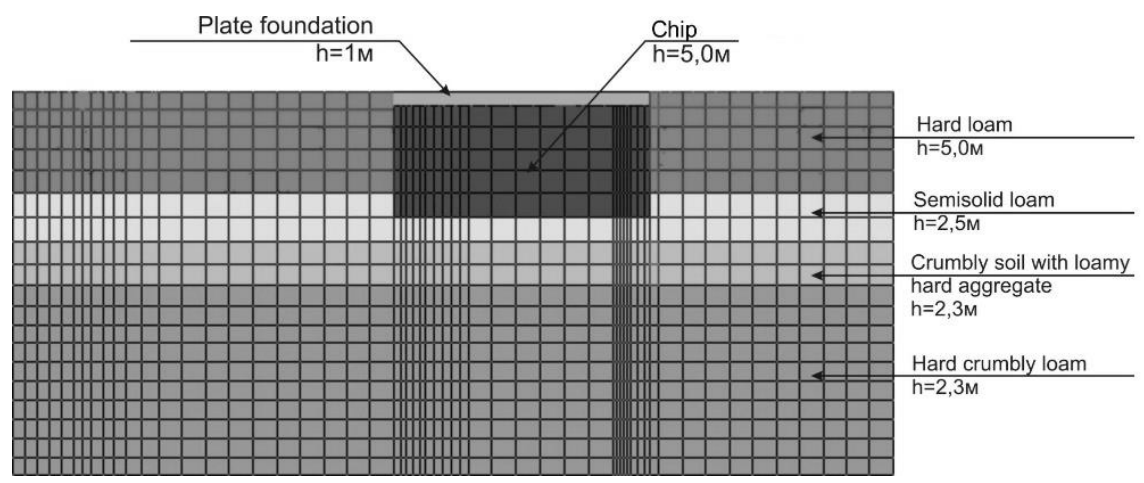

Fig. 5. Engineering-geological elements.

Before vertical displacement measuring surveying they set reference points and deformations marks which were constant during the whole observation period. 10 geodesic marks were analyzed.

The result of measuring is a summary table of sedimentary marks in each period and the accumulated settlements. Beside that we plan to work out the settlement scheme according to measuring periods.

The scheme of accumulated settlement of he analyzed marks for the period from June, 2008 to December, 2010 is on figure 6.

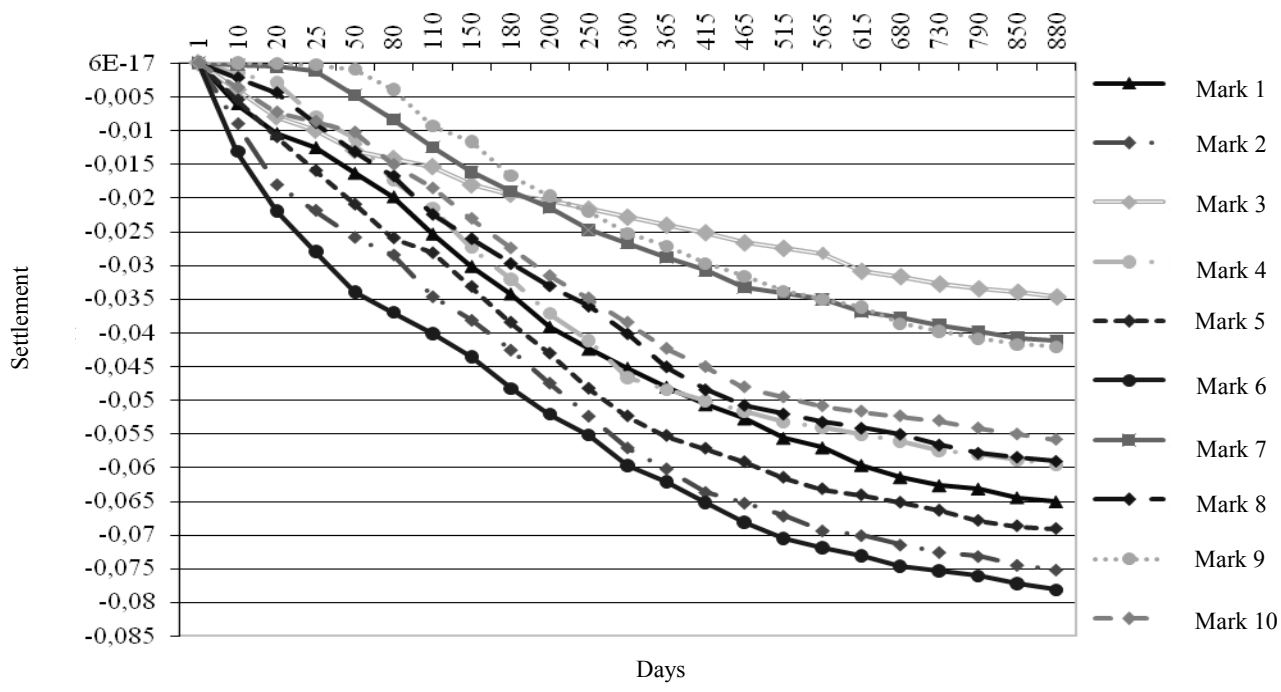

Fig. 6. Engineering-geological elements.

The settlement distribution is gradual. The max one according to the results of numeric model engineering is $87 \mathrm{~mm}$, but in accordance with the geodesic monitoring it is $78 \mathrm{~mm}$. The settlement amount of the raised building for December, 2010 does not exceed maximum allowable mark. It is $\mathrm{S}_{\mathrm{u}}=200 \mathrm{~m}$. The building tilt is insignificant and it also does not exceed the maximum allowable mark which is $i_{u}=0,004$. 


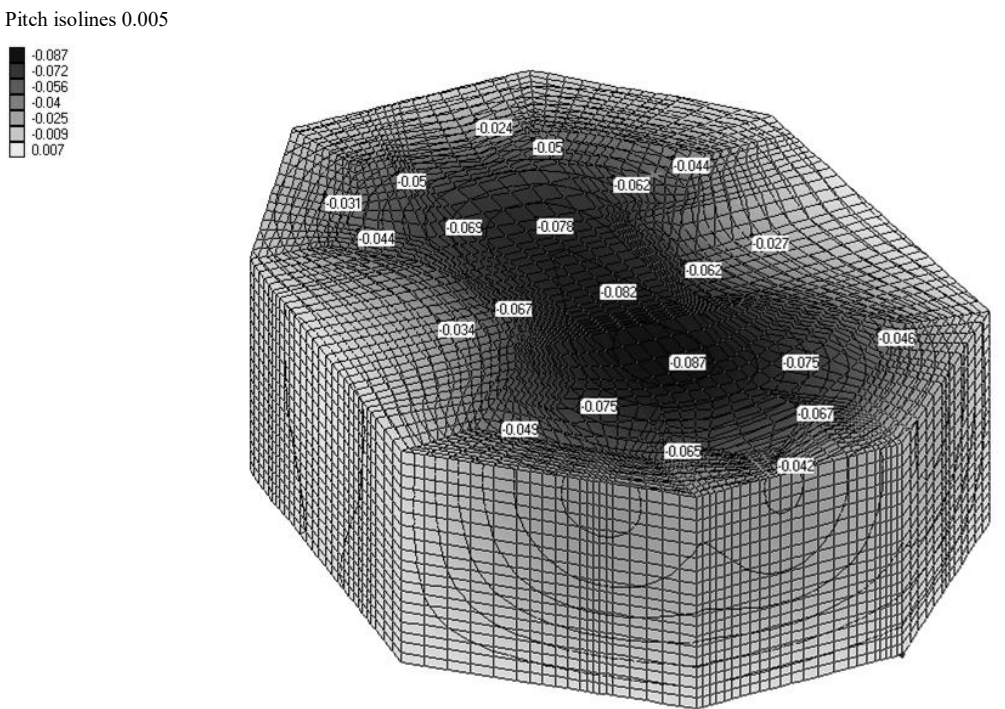

Fig. 7. Isoline of settlement plate foundation of 25 -storey building

Vertical intensities in the foundation plate of a 25 -storey building are distributed quite gradually. The max intensity marks are 280 kilopascal, which does not exceed the maximum allowable ones.

Engineering and numeric calculations show that during the installation of a $1 \mathrm{~m}$ foundation plate the building deformation is within the limits of allowable marks according to Russian norm.

\section{Conclusions}

The conducted explorations of the stress strain behavior of foundation plate of high-storey buildings have shown the possibility to use this particular type of underground constructions for building in engineering-geological conditions of Khabarovsk.

The settlement distribution is evenly due to plate foundation and chip's pillow under the plate. The geotechnical monitoring has shown the adequacy of the numeric model engineering in comparison with prototype observation. It makes it possible to conduct the numeric model engineering of the combined work of high-storey buildings on artificial and natural foundations in engineering-geological conditions of Khabarovsk.

\section{References}

1. S.A. Kudryavtsev, Numerical modeling of the freezing, frost heaving, and thawing of soils. Soil Mechanics and Foundation Engineering 5, 184 (2004)

2. S.A Kudryavtsev., V.M Ulitskii, I.I Sakharov, V.N Paramonov, Bed - structure system analysis for soil freezing and thawing using the termoground program/Soil mechanics and foundation engineering: 1-7 (Springer New York Consultants . Bureau, ISSN: 00380741, 2015)

3. S.A. Kudryavtsev, I.V Shestakov., A.V. Kazharsky, Monitoring and protection of the foundations of buildings of dangerous production plants on seasonally heaving ground 191-196 (Proc. 8th Asian young geotechnical engineers conf., Astana, Kazakhstan) 